\title{
Autosomal Recessive Polycystic Kidney Disease (ARPKD): New Insights from the Identification of the ARPKD Gene, PKHD1
}

\begin{abstract}
A review of: Ward C, Hogan M, Rossetti S, et al. 2002 The gene mutated in autosomal recessive polycystic kidney disease encodes a large, receptor-like protein. Nat Genet 30:259-269; and Onuchic L, Furu L, Nagasawa Y, et al. 2002 PKHD1, the polycystic kidney and hepatic disease 1 gene, encodes a novel large protein containing multiple IPT domains and PbH1 repeats. Am J Hum Genet 70:1305-1317
\end{abstract}

\begin{abstract}
$\mathrm{A}$ utosomal recessive PKD (ARPKD) (MIM 263200) is an important childhood nephropathy, occurring 1 in 20,000 live births. The clinical phenotype is dominated by dilatation of the renal collecting ducts, biliary dysgenesis, and portal tract fibrosis. Affected children often present in utero with enlarged, echogenic kidneys, as well as oligohydramnios secondary to poor urine output. Approximately $30 \%$ of the affected neonates die shortly after birth as a result of severe pulmonary hypoplasia and secondary respiratory insufficiency. Those who survive the perinatal period express widely variable disease phenotypes with systemic hypertension, renal insufficiency, and portal hypertension due to portal tract fibrosis as the most common clinical features (1).
\end{abstract}

Two recent studies by Ward et al. (2) and Onuchic et al. (3) found that mutations at a single locus, PKHD1 (Polycystic Kidney and Hepatic Disease 1), are responsible for all typical forms of ARPKD. Using a conventional positional cloning approach, Onuchic et al. determined that PKHD1 is a novel gene, with a minimum of 86 exons that are assembled in a complex pattern of alternative splice variants (3). The longest continuous open reading frame (ORF) is encoded by a 67 exon transcript and yields a 4074 amino acid protein, polyductin, that is predicted to have a single transmembrane spanning do-
Lisa M. Guay-Woodford

main (TM) near its carboxyl terminus and IPT (Ig-like, Plexin, Transcription factor) domains and Parallel $B \mathrm{e}$ ta-Helix $1(\mathrm{PbH} 1)$ repeats in its amino terminus. Several transcripts are predicted to encode truncated products that lack the TM and may be secreted if translated. The PKHD1 gene products are members of a novel class of proteins that share structural features with hepatocyte growth factor receptor and plexins, members of a superfamily of proteins involved in regulation of cellular adhesion and repulsion as well as cell proliferation.

Ward et al. used a comparative genomic approach to identify PKHD1 (2). These investigators determined that the renal and biliary histopathology of the pck rat model closely resembled human ARPKD and the locus mapped to an interval on rat Chromosome 9 that has conserved synteny with the human PKHD1 interval on chromosome 6 . By exploiting the genetic mapping power of the rat, they quickly refined the candidate interval, identified the disease-associated gene, and defined the pck mutation. These data led them directly to the human homologue and mutational analysis in ARPKD patients confirmed this gene as $P K H D 1$. Their characterization of PKHD1 indicated that the longest open reading frame was encoded in a
67 exon transcript. They called the predicted protein product fibrocystin and determined that this novel protein had multiple IPT domains, a single TM, 64 potential N-glycosylation sites, and two regions with similarities to proteins with unknown functions (TMEM2 and DKFZ).

Thus, two groups, working independently and using different approaches have identified the human ARPKD gene, PKHD1. Both groups determined that PKHDI is a very large gene with a 4074 amino acid protein product of the longest ORF. Both groups reported an initial mutation detection rate of only $\sim 50 \%$, suggesting that analytic challenges must be overcome before gene-based analysis is robust for clinical diagnostic testing.

However, there were important differences in these two reports. While Ward et al. described few alternative splice variants, Onuchic et al. reported that $P K H D 1$ has a complex pattern of alternative splicing that yields numerous putative protein products, some of which are likely membrane bound and some are predicted to be secreted. Therefore, the next challenge in deciphering the pathogenesis of ARPKD is to define the transcriptional and translational complexities of the PKHD1 gene in order to determine the role polyductin/fibrocystin peptides play in the terminal differentiation of renal and biliary ductules. 
1. Guay-Woodford L, Bernstein J. Other cystic kidney diseases 1999 In: Johnson R, Feehally J (eds) Comprehensive Clinical Nephrology. Mosby International, London, pp 50.1-50.12.

2. Ward C, Hogan M, Rossetti S, Walker D, Sneddon T, Wang X Kubly V, Cunningham JM, Bacallao R, Ishibashi M, Milliner DS, Torres VE, Harris PC 2002 The gene mutated in autosomal recessive polycystic kidney disease encodes a large, receptor-like protein. Nat Genet 30:259-269
3. Onuchic L, Furu L, Nagasawa Y, Hou X, Eggermann T, Ren Z, Onuchic LF, Furu L, Nagasawa Y, Hou X, Eggermann T, Ren Z, Bergmann C, Senderek J, Esquivel E, Zeltner R, Rudnik-Schoneborn S, Mrug M, Sweeney W, Avner ED, Zerres K, Guay-Woodford LM, Somlo S, Germino GG 2002 PKHD1, the polycystic kidney and hepatic disease 1 gene, encodes a novel large protein containing multiple IPT domains and $\mathrm{PbH} 1$ repeats. Am J Hum Genet 70:1305-1317.
Departments of Medicine and Pediatrics

Division of Genetic and Translational Medicine

University of Alabama at Birmingham

Kaul 740

1530 3rd Avenue South 19th Street

Birmingham, AL 35294

DOI: 10.1203/01.PDR.0000042040.36122.75

\title{
GATA1 - A Player in Normal and Leukemic Megakaryopoiesis
}

\begin{abstract}
A review of: Wechsler J, Greene M, McDevitt MA, et al. 2002 Acquired mutations in GATA1 in the megakaryoblastic
\end{abstract} leukemia of Down syndrome. Nat Genet 32:148-152

Acute megakaryoblastic leukemia (AMKL), a subtype of acute myeloid leukemia, is rare in the general pediatric population but highly prevalent in children with Down syndrome (1). Other forms of megakaryoblastic leukemia occur in childhood (2) however the AMKL of Down Syndrome is unique in many respects, including an association with abnormal megakaryopoiesis (myelodysplasia) (3). Little is known about this genetic predisposition to AMKL in Down syndrome and the preceding myelodysplasia. At the same time, the crucial role of transcription factors such as GATA1 (GATA binding protein 1 or globin transcription factor 1) during normal megakaryopoiesis (and erythropoiesis) have been established by gene inactivation experiments (reviewed in (4)) and the detection of inherited GATA1 mutations in several types of congenital dyserythropoietic anemia and thrombocytopenia (5). The report by Wechsler et al. (6) now merges the investigation of normal and malignant megakaryopoieis by providing exciting evidence linking AMKL of Down syndrome with the loss of normal GATA1 function.

Searching for GATAl mutations in blasts of several subtypes of acute myeloid leukemia, the authors discovered nucleotide insertions, deletions or point mutations in all six samples of patients with AMKL and Down syndrome that they examined. The mutations clustered in the first coding exon of GATA1 and in each case resulted in a premature stop codon preventing the synthesis of full length GATA1 pro-

\section{JoHANN K. HitzleR}

tein. Instead, a truncated protein was detected that lacked the N-terminal activation domain and showed reduced transcriptional activation. The mutant protein, however, did not differ from its wildtype counterpart in the ability to bind DNA and interact with the essential cofactor FOG1 (Friend of GATA1). All mutations were somatic and specific for AMKL in Down syndrome. They were neither found in non-Down syndrome AMKL nor in samples from patients with Down syndrome and lymphoblastic leukemia or other subtypes of acute myeloid leukemia.

This report by Wechsler et al. provides the second example in human leukemia, of how point mutations of a hematopoietic transcription factor gene generate a truncated gene product. In acute myeloid leukemia heterozygous mutations in the gene encoding $\mathrm{C} / \mathrm{EBP} \alpha$, a transcription factor crucial for granulocytic differentiation, were previously shown to result in truncated proteins interfering with the function of the wildtype protein (7). The mutations found in GATA1, however, prevent the synthesis of wildtype GATA1 altogether. Previous experiments show that lack of Gatal function during murine hematopoiesis results in excessive proliferation and impaired differentiation of megakaryocytes without leukemic transformation (4). If malignant transformation in acute myeloid leukemia is the result of at least two cooperating mutations - one promoting proliferation and a second impairing differentiation (8), the loss of GATA1 may well provide the differentiation block. The authors have defined an important pathogenic event in the disordered megakaryopoieis and malignant transformation of AMKL in Down syndrome. The next challenge will be to define the contribution of the gene(s) on chromosome 21 that cooperate with mutations of GATAl to cause AMKL.

1. Zipursky A, Poon A, Doyle J 1992 Leukemia in Down syndrome: a review. Pediatr Hematol Oncol 9:139-149

2. Ma Z, Morris SW, Valentine V, Li M, Herbrick JA, Cui X, Bouman D, Li Y, Mehta PK, Nizetic D, Kaneko Y, Chan GCF, Chan LC, Squire J, Scherer SW, Hitzler JK 2001 Fusion of two novel genes, RBM15 and MKL1, in the $t(1 ; 22)(p 13 ; q 13)$ of acute megakaryoblastic leukemia. Nat Genet 28:220-221

3. Zipursky A, Thorner P, De Harven E, Christensen H, Doyle J 1994 Myelodysplasia and acute megakaryoblastic leukemia in Down's syndrome. Leuk Res 18:163-171

4. Shivdasani RA 2001 Molecular and transcriptional regulation of megakaryocyte differentiation. Stem Cells 19:397-407

5. Nichols KE, Crispino JD, Poncz M, White JG, Orkin SH, Maris JM, Weiss, MJ 2000 Familial dyserythropoietic anaemia and thrombocytopenia due to an inherited mutation in GATA1. Nat Genet 24:266270

6. Wechsler J, Greene M, McDevitt MA, Anastasi J, Karp J, Le Beau MM, Crispino JD 2002 Acquired mutations in GATA1 in the megakaryoblastic leukemia of Down syndrome. Nat Genet 32:148-152

7. Pabst T, Mueller BU, Zhang P, Radomska HS, Narravula S, Schnittger S, Behre G, Hiddemann W, Tenen DG 2001 Dominant-negative mutations of CEBPA, encoding CCAAT/enhancer binding protein-alpha (C/EBPalpha), in acute myeloid leukemia. Nat Genet 27:263-270

8. Gilliland DG, Tallman MS 2002 Focus on acute leukemias. Cancer Cell 1:417-420

Division of Hematology/Oncology and Program for Developmental Biology

The Hospital for Sick Children

555 University Avenue

Toronto, Ontario M5G 1 X8 Canada

DOI: 10.1203/01.PDR.0000042041.36122.3C 